\title{
Sulfur and Lead Isotopic Geochemistry of the Mayuan Pb-Zn deposit in Shanxi Province: Implications for ore-forming material source
}

\author{
H. Wang \\ Faculty of Land Resources Engineering, Kunming University of Science and Technology, Kunming, China \\ Y. S. Li* \\ Development and Research Center of China Geological Survey, Beijing, China
}

Corresponding author: Y. S. $\mathrm{Li}$

\begin{abstract}
Mayuan Pb-Zn ore deposit is tectonically located in the southeastern margin of the Beiba Arch in the northern of Yangtze Plat. Its orebodies occur in the Upper Sinian Dengying Formation dolomite. Sulfide minerals are selected from the deposit for sulfur and lead isotope compositional analyses. The $\delta^{34} \mathrm{~S}$ values of sulfide minerals vary from $15.5 \%$ to $19.6 \%$ and the average is $17.67 \%$, indicating that the sulfur was mainly derived from marine sulfate reduction and reduced sulfurs that were probably derived from thermochemical sulfate reduction (TSR). The ${ }^{206} \mathrm{~Pb} /{ }^{204} \mathrm{~Pb}$ values vary from $17.62 \% \sim 18.02 \%$ and the range is $0.4 \%$, the ${ }^{207} \mathrm{~Pb} /{ }^{204} \mathrm{~Pb}$ values vary from $15.49 \sim 15.65 \%$ and the range is $0.16 \%$, and the ${ }^{208} \mathrm{~Pb} /{ }^{204} \mathrm{~Pb}$ values vary from $37.57 \sim 38.35 \%$, the range is $0.78 \%$. The uniformity of lead isotope composition displays the same feature as normal lead. The $\mathrm{Pb}$ isotope compositions of these sulfide minerals are same to that of the upper crustal lead according to the Zartman diagrams and the $\triangle \beta-\triangle \gamma$ diagrams, implying that $\mathrm{Pb}$ may come from rocks in the Upper crust. Based on the geochemical characteristics of the sulfur and lead isotope compositions from the Mayuan $\mathrm{Pb}-\mathrm{Zn}$ deposit, the ore -forming materials may derived from the basement.
\end{abstract}

KEYWORD: Mayuan; Mayuan Pb-Zn deposit; lead isotope; sulfur isotope; sources of ore-forming material

\section{INTRODUCTION}

$\mathrm{Pb}-\mathrm{Zn}$ deposits are widely distributed in the carbonate strata in the western of the Yangtze Plate, with the host rocks ranging in age from the Sinian to the Permian but mostly Sinian (Wang et al,2001,2002;Zhang et al.,2005;Rui et al.,2004). In recent years, many progresses in $\mathrm{Pb}-\mathrm{Zn}$ exploration have been made in the northern margin of the Yangtze Plate, including the Beiba periphery $\mathrm{Pb}-\mathrm{Zn}$ mineralization zone in Shanxi Province .The Mayuan $\mathrm{Pb}-\mathrm{Zn}$ deposit is located near the southern margin of the Beiba Arch in Nanzheng, Shanxi, and is presently in production. Previous studies have been carried out on the geological characteristics, geochemistry as well as mineralization age. But there are less than at the ore-forming material sources. In this paper, the $\mathrm{S} 、 \mathrm{~Pb}$ stable isotope geochemistry are used to reveal the source of sulfur and lead in the lead-zinc ore and to discuss the genesis of deposit.

\section{GEOLOGICAL BACKGROUND}

\subsection{Regional geological outline}

The Mayuan $\mathrm{Pb}-\mathrm{Zn}$ deposit is situated in the northern margin of the Yangtze Plate, in the southern margin of the Beiba Arch the exposed strata in the ore field are mainly Middle-Upper Proterozoic Huodiya Group, Upper Sinian Dengying Formation, and Lower Cambrian Guojiaba Formation. The $\mathrm{Hu}-$ odiya Group is mainly composed of meta-volcanic clastic rocks, the Dengying Formation is primarily of dolostone and sandstone, and the Guojiaba Formation is primarily of carbonaceous shale. The deposit is restricted in Upper simian Dengying Formation.

\subsection{Geological characteristics of deposit}

The Mayuan $\mathrm{Pb}-\mathrm{Zn}$ deposit is located in the Nanmushu-Jiandongzi area which is restricted to the stratabound brecciated dolostone. The main ore bodies exhibit a variety of stratiform, platy, nest like, and lenticular forms. The predominant ore minerals are sphalerite and galena with minor pyrite and other sulfides. The gangue minerals are mainly dolomite followed by quartz, calcite and minor fluorite and asphalt. The ore textures are medium to coarse grained, euhedral, and the ore structures are mainly brecciated, with minor vein massive and stockwork structures. The wall rock alteration includes dolomitization silication, pyritization and baratiza- 
tion.Based on field observation and rock ore appraisal, Ma Yuan lead-zinc deposit can divided into two metallogenic stages; Pyrite-quartz stage and and dolomite- sphalerite-galena stage .

Tab.1 Metallogenic element abundance of strata in northern margin of the Yangtze landmass (Hou et al, 2007)

\begin{tabular}{|c|c|c|c|c|}
\hline \multirow{2}{*}{ No. } & \multirow{2}{*}{ Name of formation rock } & \multirow{2}{*}{ Lithology(Sample) } & \multicolumn{2}{|c|}{ Element background content $\left(\times 10^{-6}\right)$} \\
\hline & & & $\mathrm{Pb}$ & $\mathrm{Zn}$ \\
\hline 1 & $\begin{array}{l}\text { Guojiaba Formation } \\
\qquad\left(\in_{1} g\right)\end{array}$ & Carbonaceous slate(13) & 22 & 66 \\
\hline 2 & Dengying Formation $\left(Z_{2} d n\right)$ & Sandstone, marble(105) & 12 & 71 \\
\hline 3 & Huodiya Group $\left(\mathrm{Pt}_{2-3} \mathrm{H}\right)$ & marble(2) & 50 & 300 \\
\hline 4 & Bikou Group $\left(\mathrm{Pt}_{2-3} \mathrm{bk}\right)$ & meta-volcanic rock(60) & 18 & 124 \\
\hline 5 & $\operatorname{Granite}\left(\gamma_{2-3}\right)$ & Granite(2) & 30 & 60 \\
\hline 6 & $\begin{array}{l}\text { Rock of Basement } \\
\text { (average) }\end{array}$ & (64) & 19 & 128 \\
\hline 7 & Clarke number & & 15 & 86 \\
\hline
\end{tabular}

\section{S AND PB ISOTOPIC CHARACTERISTIC}

$\mathrm{S}$ isotope analysis show that the $\delta^{34} \mathrm{~S}$ values of sphalerite, galena and pyrite range from 15.6 to $19.4 \%$ showed in the sulfur isotope histogram, indicating that sulfur derived from marine sulfate reduction, similar to the origin of sulfur in almost all $\mathrm{Pb}$ $\mathrm{Zn}$ deposits enriched heavy sulfur (Cheillet et al, 1996). In sum, sulfur in ore-forming fluid of Mayuan mining area may be the products of marine sulfate reduction from strata.

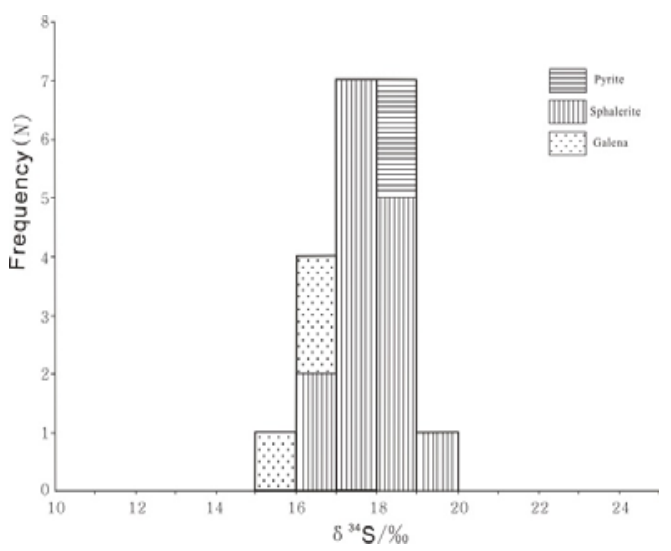

Fig.1 Sulfur isotopic histogram of Mayuan lead-zinc deposits

The $\mathrm{Pb}$ isotope analysis shows that the ${ }^{206} \mathrm{~Pb} /{ }^{204} \mathrm{~Pb}$ values range from 17.62 to $18.02 \%$, the ${ }^{207} \mathrm{~Pb} / 204 \mathrm{~Pb}$ values are 15.49 to $15.65 \%$ and the ${ }^{208} \mathrm{~Pb} /{ }^{204} \mathrm{~Pb}$ values are 37.57 to $38.35 \%$. In $\mathrm{Pb}$ isotope diagram proposed by Zartman et al (Zartman et al,1981), the $\mathrm{Pb}$ derived from the Upper crust or orogenic belts. The $\mu$ values of $\mathrm{Pb}$ isotope are 9.31 to 9.63 , showing the characteristic of crust-mantle mixing. Based on lead and zinc contents in Sinian, Cambrian and Huodiya group (table 1), lead and zinc contents in Huodiya group are more than three times higher than the clark value, so the metallogenic elements $\mathrm{Pb}-\mathrm{Zn}$ may mainly come from the basement. Cambrian Guojiaba carbonaceous slate enrich organic matter, and the decomposition of the organic matter contributes the reduction of sulfate.

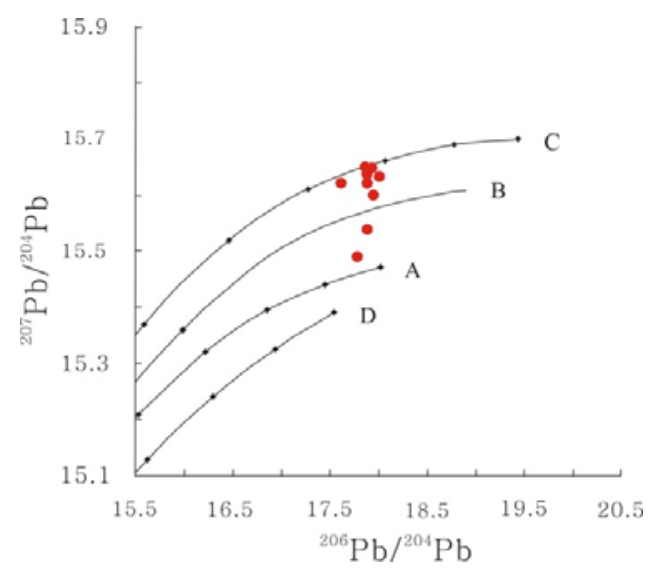

Fig.2.Lead isotopic compositions of ore minerals from Mayuan $\mathrm{Pb}-\mathrm{Zn}$ deposit (Zartman et al.1981)

Mantle B- orogenic blet C- Upper crust D-Lower crust

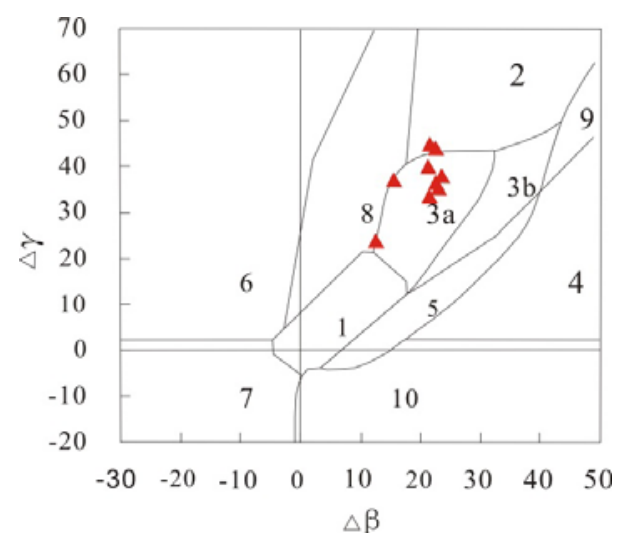

Fig.3.Lead isotopic compositions of ore minerals from Mayuan $\mathrm{Pb}-\mathrm{Zn} \operatorname{deposit}(\mathrm{Zhu}$ et al,1993)

1-Mantle derived lead; 2-Upper crust lead ;3-Mixed crust mantle subduction zone lead ; (3a-Magmatism,3b-Sedmentation) 4Chemical sedmentation lead;5-Submarine hydrothermal lead ; 6-Medium metamorphic lead ;9-Ancient shale upper crust lead; 10-Retrograde metamorphic lead 
Based on the sulfur and lead isotope analysis of Ma Yuan pb-zn deposit the source of ore-forming materials mainly come from the Upper crust. According to Tab.1 Metallogenic element abundance of strata in northern margin of the Yangtze landmass we can conclude that ore-forming materital mainly derived from basement rock and partly derived from Carbonaceous slate of Guojiaba Formation. Otherwise the Carbonaceous slate of Guojiaba Formation can provide rich in organic matter. The decomposition of the organic matter is benefit to reduction of sulfate.

In sum, we can summarize the ore-forming processes of Mayuan $\mathrm{Pb}-\mathrm{Zn}$ deposit. $\mathrm{Pb}$ and $\mathrm{Zn}$ in the basement rock and Carbonaceous slate are extracted by underground geothermal brine, with the Simian dolomite dissolved. When ore-forming fluid migrate to dolomite breccia belt rich in organic matter, Oreforming matters $\mathrm{Pb}$ and $\mathrm{Zn}$ precipitate because of reduction, with hydrothermal dolomite forming. Guojiaba Formation Carbonaceous slate.

\section{CONCLUSION}

(1)The $\delta^{34} \mathrm{~S}$ values of Mayuan lead-zinc mine are near to that of marine sulfate, indicating that the sulfur of ore-forming fluid is derived from the thermochemical sulfate reduction of marine sulfate in strata.

(2) The mineralizing material $\mathrm{S}$ and $\mathrm{Pb}$ are mainly derived from basement and Cambrian Guojiaba formation carbonaceous slate provide abundant reductant for mineralization.

\section{REFERENCES}

Cheilletz A, Giuliani G.1996.The genesis of Colombian emeralds: A restatement. Mineralium Deposita,31:359-364

Hou mantang, Wang guodang, Deng shengbo and Yang zongrang 2007.Geology and Genesis of The Mayuan LeadZinc Mineralization Belt in Shanxi Province.40(1): 42 60.

Rui Zongyao, Ye Jinhua, Zhang Lisheng, Wang Longsheng and Mei Yanxiong,2004.Pb-Zn deposits on the perimeter of the Yangtze Craton and on the margin of its uplifts. Geology in china ,31(4):337-346.

Wang Jiangzhen, Li Chaoyang, Li Zeqin and Liu jiajun, 2001. The geological setting, characters and origin of Mississippi Valley-Type $\mathrm{Pb}-\mathrm{Zn}$ deposits in Sichuan and Yunnan Provinces .Geology-Geochemistry:29(2):41-45.

Wang Jiangzhen, Li Chaoyang, Li Zeqin, Li Baohua and Liu Wenzhou,2002.The comparison of Mississippi Valley-Type lead-zinc deposit in southwest of China and in mid-continent of United States.Bulletin of Mineralogy,Petrology and Geochemistry, 21(2):127-132

Zartman R E.Doe B R.Plumbottectonics-The model[J]. Tectonophysics, 1981,175(1-2):135-162.

Zhang Changqin, Mao Jingwen,Wu Suoping,Li Houmin, Liu Feng, Guo Baojian and Gao Derong, 2005. Distribution ,characteristics and genesis of Mississippi Valley-Type lead-zinc deposits in Sichuan-Yunnan-Guizhou area.Mineral Deposits,24(3):336-348
Zhu Bing-quan .Tri-dimension special topological diagrams of ore lead isotopes and their appliaction to the division of geochemical provinces and mineralizations.Geochimica, 1993(3): 209-216. 